\begin{tabular}{c} 
International Journal of Engineering \& Technology, $7(4.37)(2018) 48-52$ \\
International Journal of Engineering \& Technology \\
SPC \\
Website: Www.Sciencepubco.Com/Index.Php/IJET \\
Research Paper \\
\hline
\end{tabular}

\title{
Compressive Strength of Cement Mortar with white cement and limestone
}

\author{
Fadya Saadi Klak ${ }^{1}$, Aziz I. Abdulla ${ }^{2 *}$ \\ Civil Eng. Dept., Tikrit University \\ *Corresponding author E-mail: lan914@gmail.com
}

\begin{abstract}
In this paper, the properties of cement mortar were studied after replacing part of the cement with other materials namely white cement, and limestone powder. The experimental test results were compared with normal cement mortar. Three kinds of mixtures were used. In the first type, cement was replaced with white cement only with different rates $(5 \%, 10 \%, 15 \%, 20 \%, 25 \%, 30 \%, 35 \%, 40 \%, 45 \%$, and $50 \%$ ), the best ratio was determined, namely, the percentage that gave the highest value in the compression strength test, which is the compensatory ratio of $25 \%$. In the second type of mixtures, a fraction of the cement was replaced with limestone powder only and with different rates $(10 \%, 20 \%, 30 \%, 40 \%$, and $50 \%)$. In the third type, cement was replaced by $25 \%$ white cement and different limestone powder ratio. Super-plasticizer (SP) was used with $1.5 \%$ rate. The compressive strength, absorption, the dry and wet density of all mixtures was measured. The results showed that the use of white cement instead of cement led to the production of cement mortar different in colors and better specifications, especially when the compensation rate was $25 \%$. The results also showed that limestone powder gave a remarkable improvement in the properties of white cement mortar.
\end{abstract}

Keywords: Cement mortar, Compressive strength, Limestone, Partial replacements, White cement.

\section{Introduction}

In recent times, the use of higher grades of ordinary Portland cement are being widely encouraged in most of the advanced countries to suit the conditions for producing high strength brick work. A number of studies have been carried out to investigate the partial replacement of cement by different materials. For example, white cement has been used and, it has been observed that brittle failure has been occured in relatively high strength mortars and the failure was sudden, however the physical properties of cement based composites are primarily affected by the white cement ratio, the chemical composition, micro-structure and poregeometry of the cementitious materials, properties of aggregates, properties of cement-aggregate ratio and properties of cement-aggregate interfacial zone[9]. In spite of very significant developments in the cement and concrete technology, the behavior of mortars made with high strength and high performance cementitious composite materials depends on the performance of the mortar matrix [8].

The demand for high quality sustainable materials has increased and encouraged the researchers in building technology to find new alternatives. Here is one of these researchers. Because limestone is hard enough to resist weathering but usually soft enough to be worked (cut and carved) by stonemasons. It is used to make cement. From another hand, White Portland cement differs physically from gray cement only in terms of its color. Its setting behavior and strength development are essentially the same as that expected in gray cement. Thus, by using these materials as a replacement of cement, it is expected to get high strength cement with off-white color. Several studies mention the partial replacement of cement $[6,8]$, without revealing a great improvement in mechanical properties. In a previous paper, Chi-Liang[1] de- scribed the strength of cement replaced by waste materials (sewage sludge SSA) with pozzolanic characteristics and the prepara

tions of this mortar. Unfortunately, due to the slow hydration rate of SSA, cement mixed with high volumes of SSA has lower strength development and lower durability than ordinary Portland cement. Previous research on using SSA to replace cement showed that most mixtures of greater than $20 \%$ replacement had poor early mechanical strength. When the replacement ratio reached $50 \%$, the compressive strength $(\mathrm{Sc})$ was only $14 \%$ of that of the control cement mortar after a curing period of 28 days [6]. $\mathrm{Li}$ and Zhao (2003) [4] found that mixing coal combustion fly ash (FA) and ground granulated blast furnace slag (GBS) to replace cement achieved better Sc than FA alone after a curing period of 28 days. Combining FA and GBS as binders in concrete achieved higher strength levels at all ages compared with conventional concrete (Papayianni and Anastasiou, 2010). This shows that GBS can accelerate the hydration rate of FA when incorporated with FA as a binder in cement mortar. Therefore, the present study examined the possibility of blending cement with increasing replacement ratios of SSA, GBS, and/or FA to reuse these waste materials and to accelerate the hydration and pozzolanic reactions of SSA in cement mortar.

Moreover, Isaia et al. (2003)[3] found that adding calcium to pozzolan, which has a low calcium/silicon ratio, enhanced the hydration reaction for the formation of calcium silicate hydrate (CSH) gels and further improved the mechanical strength of highperformance concrete. Consequently, the present study also attempted to modify the properties of SSA through the addition of calcium. The effect of calcium on the pozzolanic reaction of the modified SSA was evaluated. In addition, the hydration characteristics of the cement mortars prepared by blending cement with 
SSA or modified SSA, GBS, and/or FA were examined at different curing ages. These results indicated that the incorporation of other activators to accelerate the hydration of SSA should be studied further. From other hand, freeda[2] introduce a study included finding a way for enhancing the strength properties of mortar with fly ash as partial replacement with fine aggregate and with the cement in the cement mortar.

In this paper, we report an attempt to study the feasibility of using the white Portland cement and the limestone as a partial replacement of cement for making high strength off-white cement and test its strength and density after treated with water for 24 hours. Test results are presented and discussed here in this paper.

\section{Materials and Methods}

Experimental Works

\section{Materials}

\subsection{Cement}

Iraqi standard ordinary Portland cement produced by (UUC united Cement Company). The chemical and physical properties as shown in table (1).

Table 1: Physical and chemical properties of cement

\begin{tabular}{|l|l|l|}
\hline Description & Content \% & $\begin{array}{l}\text { Limit of Iraqi specification } \\
\text { No. 5/1984 }\end{array}$ \\
\hline Calcium oxide, $\mathrm{CaO}$ & 64.5 & ----- \\
\hline Silica, SiO2 & 13.4 & ----- \\
\hline Alumina, Al2O3 & 4.6 & ------ \\
\hline Iron Oxide, Fe2O3 & 3.5 & ----- \\
\hline Magnesia, MgO & 2.5 & $5 \%$ Max. \\
\hline Sulfate, SO3 & 1.1 & $2.8 \%$ Max. \\
\hline Loss of Ignition, (L.O.I) & 0.95 & $4 \%$ Max. \\
\hline Insoluble material & 1.05 & $1.5 \%$ Max. \\
\hline $\begin{array}{l}\text { Lime Saturation Factor, } \\
\text { (L.S.F) }\end{array}$ & 0.9 & $(0.66-1.02)$ \\
\hline $\begin{array}{l}\text { Specific surface area, } \\
\text { (m2/kg) }\end{array}$ & 301.5 & $>250 \mathrm{~m} 2 / \mathrm{kg}$ \\
\hline $\begin{array}{l}\text { Initial setting, hrs : min } \\
\text { Final setting, hrs : min }\end{array}$ & $0: 55$ & $\begin{array}{l}>45 \mathrm{~min} \\
<10 \mathrm{hrs}\end{array}$ \\
\hline 3-day f'c MPa & 28.7 & $>15 \mathrm{MPa}$ \\
\hline
\end{tabular}

\subsection{Fine Aggregate}

Graded fine aggregate from Toz city. The chemical and physical properties as shown in table (2).

Table 2: Grading, chemical and physical properties of fine aggregate

\begin{tabular}{|c|c|c|c|}
\hline \multicolumn{4}{|c|}{ Grading of fine aggregate } \\
\hline Sieve size & $\begin{array}{l}\text { Cumulative pass- } \\
\text { ing \% }\end{array}$ & \multicolumn{2}{|c|}{ Limit of ASTMC33-01 } \\
\hline $9.5 \mathrm{~mm}$ & 100 & \multicolumn{2}{|l|}{100} \\
\hline $4.75 \mathrm{~mm}$ & 91.34 & \multicolumn{2}{|l|}{$95-100$} \\
\hline $2.36 \mathrm{~mm}$ & 83.8 & \multicolumn{2}{|l|}{$80-100$} \\
\hline $1.18 \mathrm{~mm}$ & 67.73 & \multicolumn{2}{|l|}{$50-85$} \\
\hline $600 \mu \mathrm{m}$ & 20.3 & \multicolumn{2}{|l|}{$25-60$} \\
\hline $300 \mu \mathrm{m}$ & 2.45 & \multicolumn{2}{|l|}{$5-30$} \\
\hline $150 \mu \mathrm{m}$ & 0 & \multicolumn{2}{|l|}{$0-10$} \\
\hline \multicolumn{4}{|c|}{ Chemical and physical properties of fine aggregat } \\
\hline Properties & Specification & $\begin{array}{l}\text { Test } \\
\text { Results }\end{array}$ & $\begin{array}{l}\text { Limits of Speci- } \\
\text { fication }\end{array}$ \\
\hline Specific gravity & ASTM C128-01 & 2.60 & \\
\hline Absorption \% & ASTM C128-01 & 2.2 & \\
\hline $\begin{array}{l}\text { Dry loose unit } \\
\text { weight, } \mathrm{g} / \mathrm{m} 3\end{array}$ & $\begin{array}{l}\text { ASTM } \\
\text { C29/C29M/97 }\end{array}$ & 1590 & \\
\hline $\begin{array}{l}\text { Sulfate content (as } \\
\text { SO3), } \%\end{array}$ & (I.O.S) No.45-84 & 0.08 & $<0.5$ \\
\hline $\begin{array}{l}\text { Material finer than } \\
0.075 \mathrm{~mm} \% \text { sieve }\end{array}$ & (I.O.S) No.45-84 & 1.3 & $<0.5$ \\
\hline
\end{tabular}

\subsection{Water}

Water available in the college campus conforming to the requirements of water or concerting and curing as per BS: $1881: 1970$.

\subsection{White Cement}

A Portland white cement was used manufactured by united cement company (Tasluja - Sulaymaniyah). The specific gravity of the cement used was 3.15.

\subsection{Limestone Obtained from natural deposits in Mosul.}

\subsection{Super-plasticizer (SP)}

Obtained from market in Salah Aladdin.

\section{Tools}

1. Cement mortar cubes of $(5 * 5 * 5) \mathrm{cm}$ are used for compressive strength test.

2. Balance with sensitivity not less than $0.1 \mathrm{~g}$.

3. A listed cylinder to measure the amount of water.

4. Universal hydraulic compression test machine.

\section{Specimens and experimental work}

In this experimental work, three types of partial replacement by weight of cement are chosen, and one type of admixture are used. A total of 138 numbers of mortar specimens were cast. The mixing proportions 1:2.5 (cement: sand by weight) when designed is satisfy the American standard (194//A ق ق \&B.S. 12 ; part $2: 1971$ )[9] with variable water cement ratio changed between (25\%-50\%) depending on the replacements and results. Three kinds of mixtures were used, the first one contained 66 numbers of mortar specimens ( 33 for 7 days age and 33 for 28 days age) with partial replacement of white cement only in a variable percentages (i.e., ratio of weight of white cement to the weight of cement), these percentages are $(0 \%, 5 \%, 10 \%, 15 \%, 20 \%, 25 \%, 30 \%, 35 \%, 40 \%$, $45 \%, 50 \%$ ), and SP as a 1.5 percent of cement weight. The second one contained 36 numbers of mortar specimens (18 for 7 days age and 18 for 28 days age) with partial replacement of limestone powder in a variable percentages (i.e., ratio of limestone powder to the weight of cement), these percentages are $(0 \%, 10 \%, 20 \%, 30 \%, 40 \%, 50 \%)$.the third one contained 36 numbers of mortar specimens (18 for 7 days age and 18 for 28 days age) with partial replacement of white cement of percentage $25 \%$ (give the best result) and limestone powder in a variable percentages (i.e., ratio of limestone powder to the weight of cement), these percentages are $(0 \%, 10 \%, 20 \%, 30 \%, 40 \%, 50 \%)$. Cement, sand, white cement, and limestone powder were mixed in dry state handy and then the required quantity of water and the SP were added and mixed thoroughly. Before casting, machine oil was smeared on the inner surfaces of the iron mold. Mortar was poured into the mold and compacted thoroughly using a standard compact machine for 2 minutes $[10,11]$. The top surface was finished by means of a trowel. The specimens were removed from the mold after $24 \mathrm{hrs}$. and then cured under water for a period of 7 and 28 days. The specimens were taken out from the curing tank just prior to the test. The tests of compressive strength were conducted using the universal hydraulic compression test machine. The test was conducted as per the relevant standard British specification $[10,11]$. the specimens were weighted before and after $24 \mathrm{hrs}$ curing. 


\section{Results and Discussions}

\subsection{Compressive Strength}

The average compressive strength of the standard mortar cubes for different mixtures are represented in figures (1),(2), and (3). The results reported are average of 3 specimens. From the figure(1), it is clear that there is an enhancing in compressive strength when replacing white cement instead of ordinary cement until percent (25\%), after this percent the enhancing decreases until it Until it approaches zero. This indicates that the compressive strength of white cement mortar increase markedly and the best increasing are when the percent of white cement in cement is $25 \%$, this increase in strength is due to the large amounts of limestone and the white limestone in composition of white cement and the small amounts of $\mathrm{Fe} 2 \mathrm{O} 3$ and $\mathrm{Mn} 2 \mathrm{O} 3$ which is reduces the pozzolanic activity of cement mortar and form calcium silicate hydrate gels to fill the capillary pores of the cement mortar. In Figure (2), by using the limestone powder, the compressive strength decreases in different percepts and for two ages comparing to figure (1), while in figure (3), replacing the ordinary cement by both white cement (25\%) and limestone powder led to increase compressive strength at age of 28 days, while there is a small decrease in compressive strength at age of 7 days comparing to figure (1). It was observed that the increase in compressive strength at age 7 was higher than at 28 days this is due to the characteristics of white cement, while The increase in compressive strength at 28 days is higher than 7 days in the limestone powder mixtures. Consequently, the compressive strength development of cement mortar with white cement replacement was better than that with limestone powder, and the total pore volume of blended cement mortars with limestone/ordinary cement replacement was less than that $\ldots \ldots$ cement/ordinary cement replacement.

\subsection{Absorption}

Figures $(4,5$, and 6$)$ shows the values of absorption $\mathrm{fc}$ It is seem that the variation is most clear in the mixes white cement only especially when the ratio of whit $(5 \%, 10 \%, 15 \%, 20 \%)$ of cement weight, after thes values became almost constant.

\subsection{Dry and Wet Density}

The variation of dry density and wet density for differ are shown in figures $(7,8,9,10,11$, and 12$)$. It is se figures that there is a little variations in dry and wet c they became constant especially in the mixes that $\mathrm{cc}$ cement only.

IT is observed during the test that the specimens faile developing small size crack on the tension side of th and also these did not break into two pieces which inc tile failure.

\section{Conclusions}

Based on the results of the present experimental work that:-

white cement improved cement mortar properties ( 1 strength, absorption, dry and wet density ) when cor limestone powder in the present of SP in two cases.

The variation in compressive strength achieved by rep cement by weight of cement in the aforesaid cement are $(28.7,80.9,83,85.7,90.7,66,64.4,37.1,7.7$, an spectively for 7 days age, and it is $(16.7,42.2,56.7,63$ $62.9,61.1,-6.9$, and -20.7$) \%$ for 28 days age.

The variation in compressive strength in limestone powder mix-compressive strength tures was as follows:
3-1. The mixtures contain only limestone powder in the aforesaid cement percentages are $(49.4,141.4,221.8,279.3$, and 325.3)\% respectively for 7 days age, and it is $(96.9,159.4,207.1,254.3$, and 281.1$) \%$ for 28 days age.

3-2. The mixtures contain limestone powder with $25 \%$ white cement in the aforesaid cement percentages are $(12,28,44,52$, and $56) \%$ respectively for 7 days age, and it is $(21.2,39.4,45.5,48.5$, and 51.5$) \%$ for 28 days age.

Using white cement as a ratio of cement weight to limit the ratio of $25 \%$ increase compressive strength, enhancing absorption, dry and wet density, while using limestone powder with white cement enhancing this properties after the ratio of $25 \%$. The presence of super-plasticizer helped to reduce the water / cement ratio without a significant increase in compressive strength and without affecting the absorption and wet and dry density.

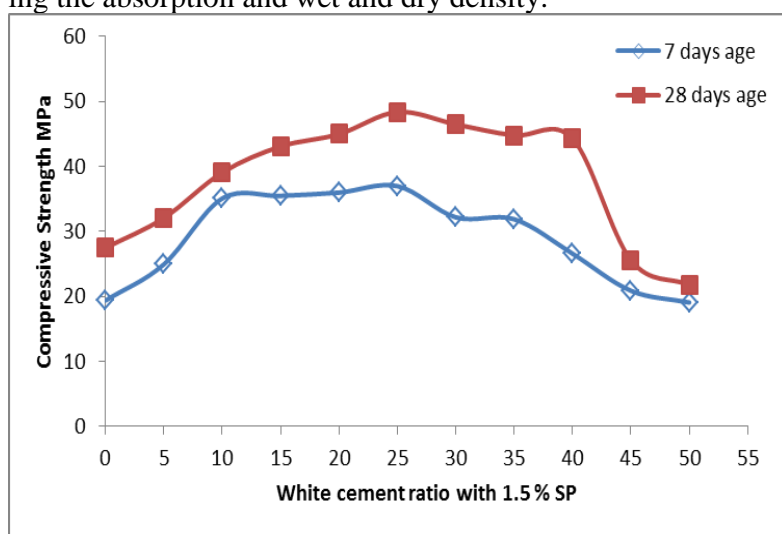

Fig.1: Effect of white cement ratio on the compressive strength

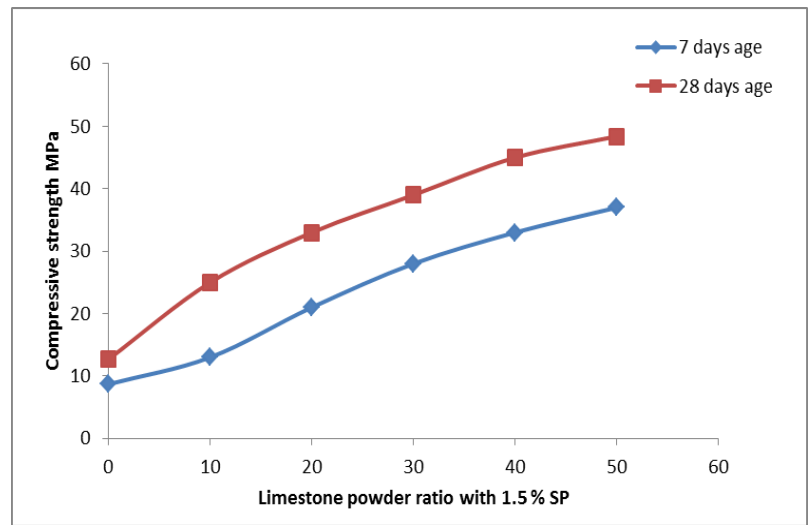

Fig.2: Effect of limestone powder on the compressive strength

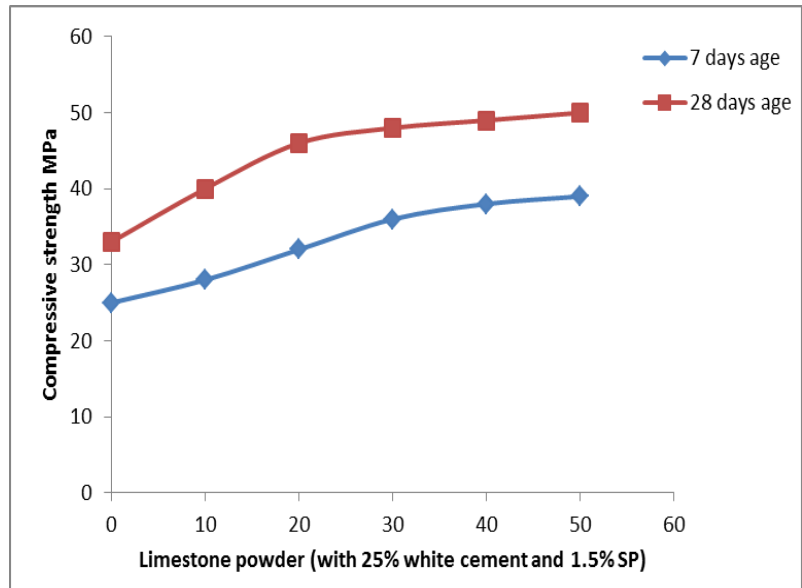

Fig. 3: Effect of limestone powder (with $25 \%$ white cement) on the 


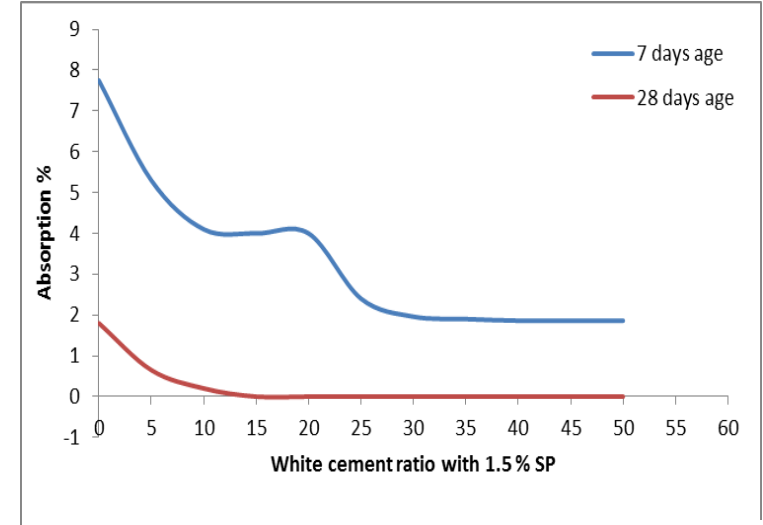

Fig.4: Effect of white cement ratio on absorptior

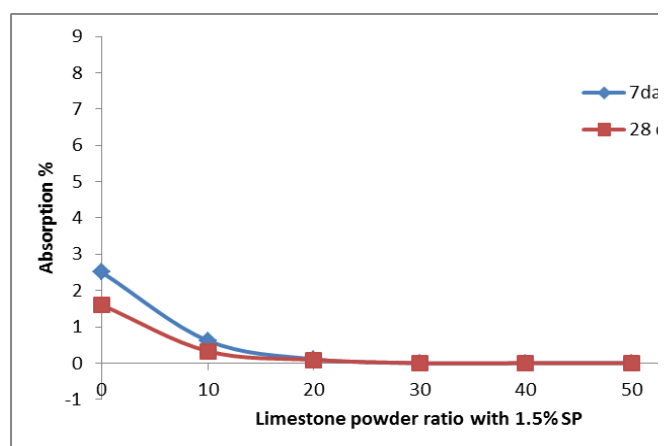

Fig. 5: Effect of limestone powder ratio on absorpt

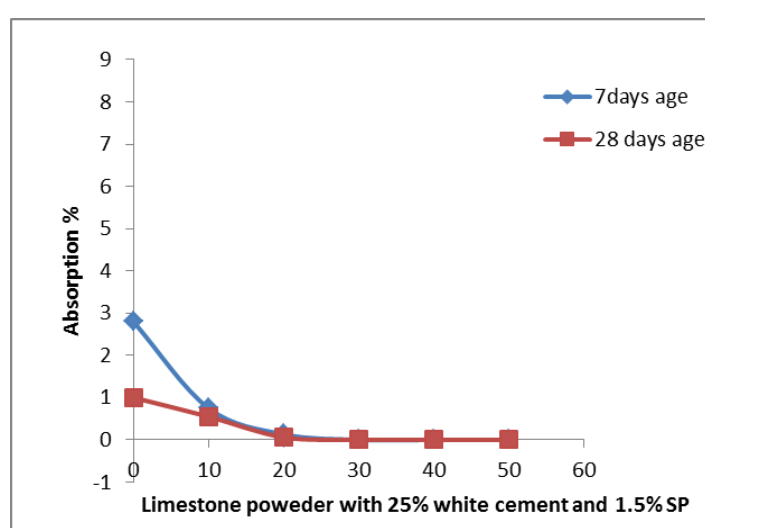

Fig. 6: Effect of limestone powder ratio with $25 \%$ white cen absorption

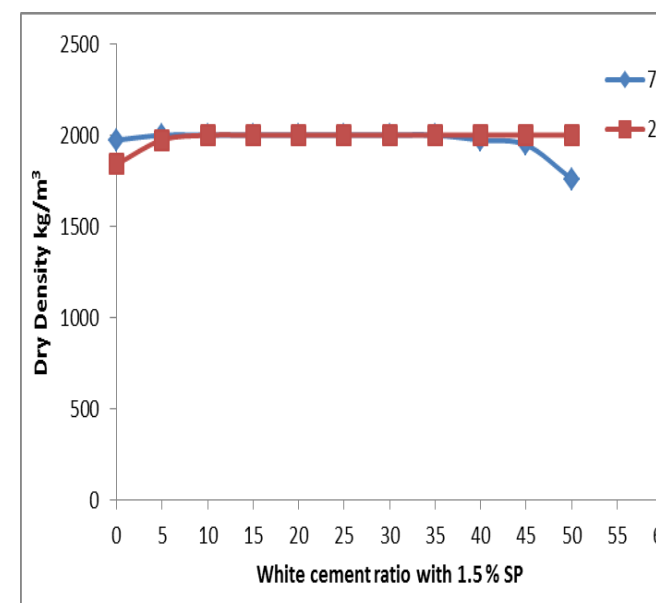

Fig. 7: Effect of white cement ratio on dry densit

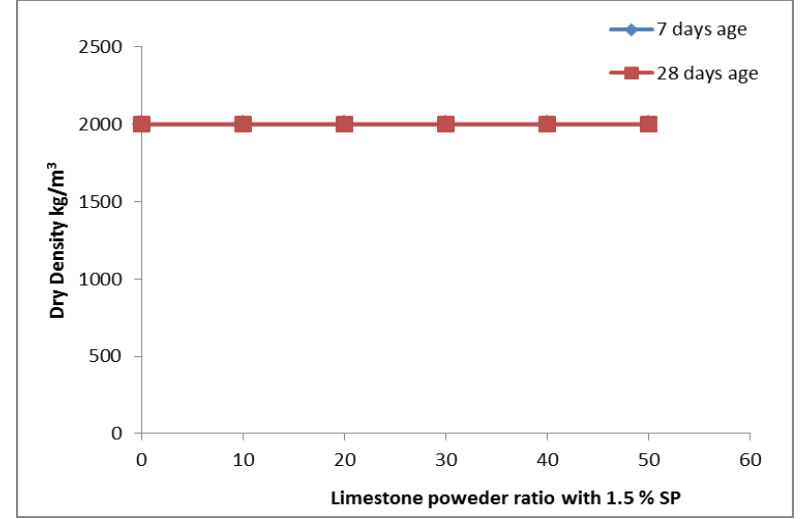

Fig. 8: Effect of limestone powder ratio on dry density

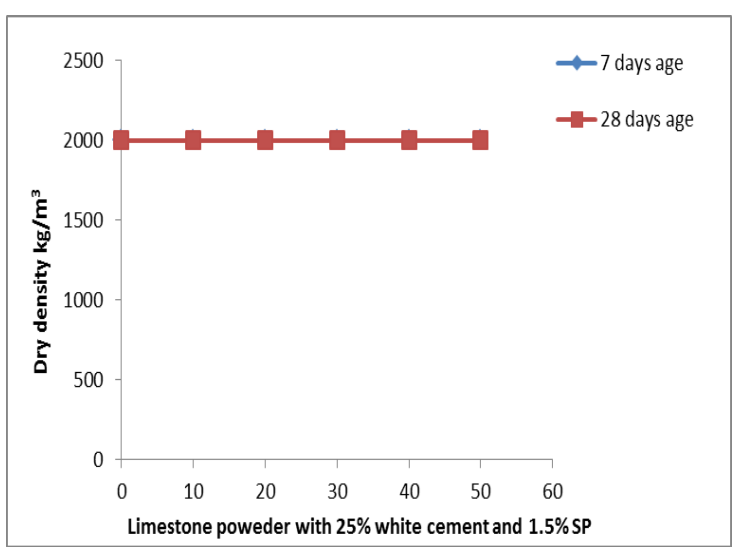

Fig. 9: Effect of limestone powder ratio with $25 \%$ white cement on dry density

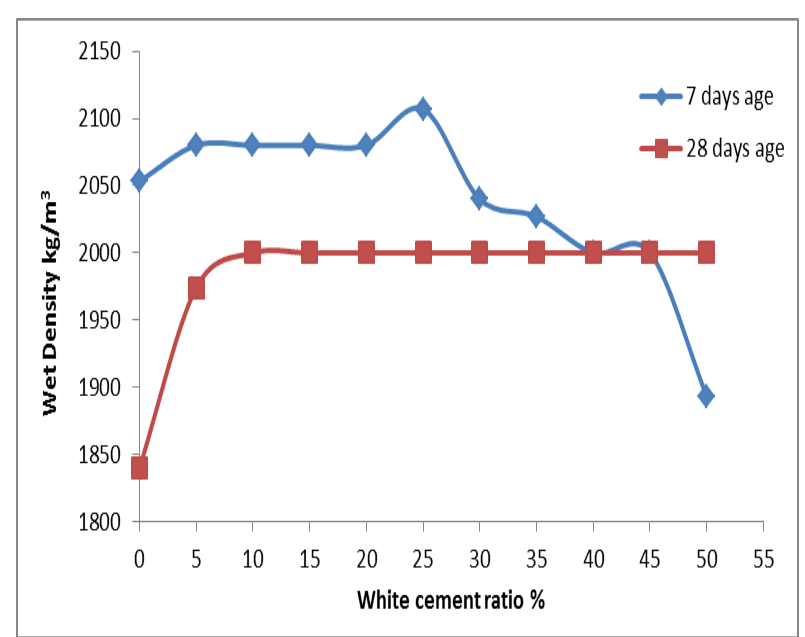

Fig.10: Effect of white cement ratio on wet density

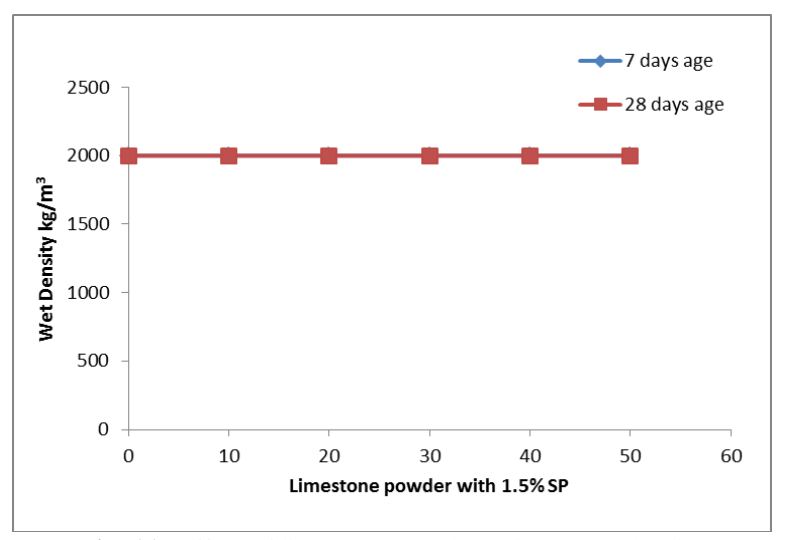

Fig. 11: Effect of limestone powder ratio on wet density 


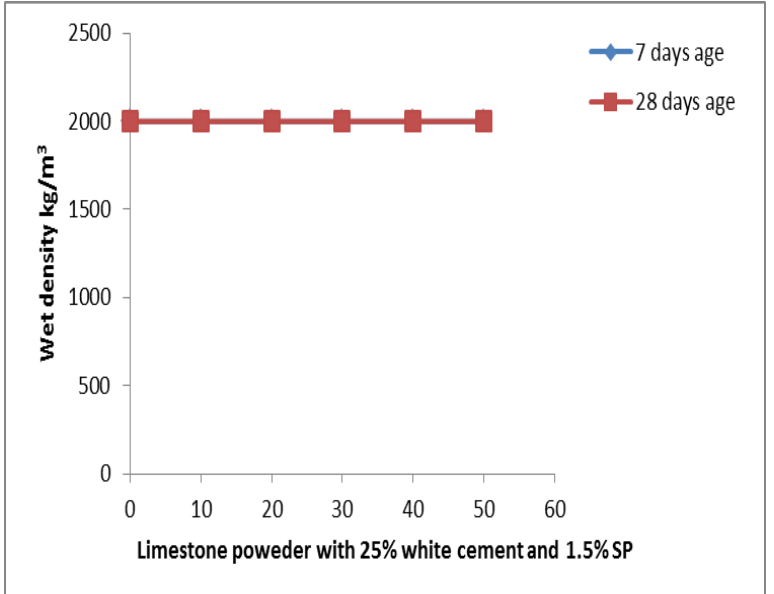

Fig. 12: Effect of limestone powder ratio with $25 \%$ white cement on we density

\section{References}

[1] Chi-Liang,Dyi-Hwa T seng, and Yue-Ze Wu. "Properties of Cement Mortar Producted from Mixed Waste Materials with Pozzolanic Characteristics". Enviromental engineering Science, Jul.29 (7) 2012, pp.638-645.

[2] C Freeda Christy \& D Tensing. "Effect of Class-F Fly Ash as Partial Replacement with Cement and Fine Aggregate in Mortar". Indian Journal of Engineering \& Materials Science, Vol17, April 2010, pp. 140-144.

[3] Isaia G.C. Gastaldini A.L.G. Moraes R. Physical and pozzolanic action of mineral additions on the mechanical strength of highperformance concrete. Cem. Concr. Compos. 2003;25:69.

[4] L.A. Palmer and D .A .Parsons. " A Study of the Properties of Mortars And Bricks And Their Relation To Bond". Bureau of Standers journals of Researches, Vol.12, May 1934, pp. 683.

[5] Li G.Y. Zhao X.H. Properties of concrete incorporating fly ash and ground granulated blast-furnace slag. Cem. Concr. Compos. 2003;25:293.

[6] Jauberthie r, Rendell F, Tamba S, Cisse IK. "Properties of Cement Rice Husk Mixture", Construction and Building Materials, Vol.17, No.4. 2003, pp. 243-239.

[7] Pan S.C. Tseng D.H. Lee C. Use of sewage sludge ash as fine aggregate and pozzolan in Portland cement mortar. J. Solid Waste Technol. Manage. 2002;28:121.

[8] Savstano A, Wardenb PG, Coutts RSP. "Potential of Alternative Fibre Cements as Building Materials for Developing Areas". Cement and Concrete Composites, 2003, Vol.25, No.6, pp. 92-585.

[9] Nevellie A M, "Properties of Concrete", Pearson Education, Pvt. Ltd, Signapore), 2000, 650

[10] 10. Moayad Nouri Al-Khalaf, Hanaa Abdel-Youssef, "Concret Technology",Center of Arabization and Publishing, Technology University, Baghdad, 1984

[11] 11. Hanaa Abdel-Youssef, Moayad Nouri Al-Khalaf, "Tests in Concrete Technology", Center for Arabization and Publishing, University of Technology, Baghdad. 